\title{
Microstructure Changes of Nickel-Base Superalloys Induced by Interaction with Femtosecond Laser Beam
}

\author{
S. Petronic ${ }^{a}$, S. Drecun-Nesic ${ }^{a}$, A. Milosavluevic ${ }^{a}$, A. $_{\text {Sedmak }}^{a}$, M. Popovic $^{b}$ \\ AND A. KOVACEVIC ${ }^{b, *}$ \\ ${ }^{a}$ Faculty of Mechanical Engineering, University of Belgrade, Belgrade, Serbia \\ ${ }^{b}$ Institute of Physics, University of Belgrade, Belgrade, Serbia
}

\begin{abstract}
The investigation was performed on nickel-base superalloys, with nickel being the most influential alloying ingredient. After thermo-mechanical preparation and corresponding processing, femtosecond laser beam machining has been performed. The laser wavelength was $800 \mathrm{~nm}$. The exposition time, during which the samples have been exposed to the pulses of femtosecond laser beam varied, as well as the average output power. The changes of both the output power and the exposition time enabled the samples to be irradiated with different total energy during each exposition. The changes in samples microstructure were observed with optical and scanning electron microscopy, with energy-dispersive spectrometry, and analyzed as well. Microhardness measurements of both base material and ablated spots have been performed.
\end{abstract}

PACS numbers: 01.55.+b, 42.62.-b, 81.05.Bx

\section{Introduction}

Nickel-base superalloys have wide use in the environments of elevated temperature and pressure. These materials are applied for many applications that include chemical and metallurgical processing, oil and gas extraction and refining, energy generation, and aerospace propulsion [1]. They are mostly used in gas turbine engines for combustion zone components, afterburners, tailpipes, casing, liner, exhaust ducting, bearing housing and many others [2]. The most desirable characteristic is their ability to withstand loadings at an operating temperature close to their melting point [3]. Superalloys Hastelloy X and Nimonic 263, investigated in this work, consist of a number of chemical elements added to the austenite matrix to improve their chemical, physical and mechanical properties at elevated temperature.

Although the interaction of ultrashort laser pulses with solid targets has been investigated for some time [4-7], femtosecond laser beam material interaction has generated a lot of interest in recent years [8-10]. It is of interest particularly in the ablation process, because the fs pulse duration is less than the typical electron-lattice thermalization time. This feature enables the irradiated material to be driven into an extremely excited state followed by a rapid quenching [11].

\section{Experiment}

In the experiment, the samples of nickel-base superalloys have been exposed to the pulses of fs laser beam.

\footnotetext{
* corresponding author; e-mail:

Aleksander.Kovacevic@phy.bg.ac.yu
}

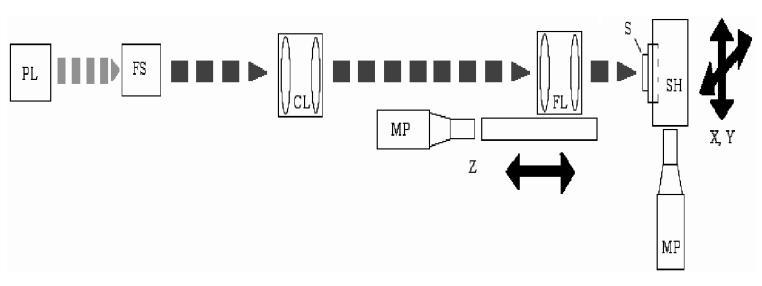

Fig. 1. Experimental setup for laser beam interaction with solid targets (PL - pump laser, FS - femtosecond laser, CL - collimating lens, FL - focusing lens, MP - micropositioners, SH - sample holder, S - sample, $\mathrm{X}, \mathrm{Y}, \mathrm{Z}$ - directions of movement).

TABLE I

The chemical composition of Hastelloy X (1) and Nimonic $263(2)$.

\begin{tabular}{c|c|c|c|c|c|c|c|c|c|c|c}
\hline \hline $\begin{array}{l}\text { Element } \\
\text { Alloy }\end{array}$ & $\mathrm{Ni}$ & $\mathrm{Cr}$ & $\mathrm{Mo}$ & $\mathrm{Mn}$ & $\mathrm{Si}$ & $\mathrm{Fe}$ & $\mathrm{C}$ & $\mathrm{Al}$ & $\mathrm{Co}$ & $\mathrm{W}$ & $\mathrm{Ti}$ \\
\hline$(1)$ & 47.2 & 19.8 & 9 & 0.2 & 0.8 & 20.5 & 0.2 & 0.2 & 1.5 & 0.6 & $\mathrm{~N} / \mathrm{A}$ \\
$(2)$ & 50 & 20 & 5.9 & 0.5 & 0.3 & 0.5 & 0.06 & 0.5 & 20 & $\mathrm{~N} / \mathrm{A}$ & 2.2
\end{tabular}

The chemical composition of the superalloys is listed in Table I. The experimental setup is presented in Fig. 1.

Pump laser (PL), Coherent Verdi $10 \mathrm{~W} \mathrm{Nd}^{3+}$ :YAG $532 \mathrm{~nm} \mathrm{CW}$, provides excitation for a femtosecond laser (FS), Coherent Mira 900. The characteristics of the femtosecond laser are: wavelength $800 \mathrm{~nm}$, pulse duration $160 \mathrm{fs}$, pulse repetition rate $76 \mathrm{MHz}$, pulse energy $\approx 30$ nJ. Focus length of a focusing lens is $5 \mathrm{~mm}$.

The laser average output power varied from $\approx 1.2$ to $\approx 1.8 \mathrm{~W}$. The exposition time has been changed from 
15 to $60 \mathrm{~s}$ (for Hastelloy $\mathrm{X}$ ) and from 60 to $180 \mathrm{~s}$ (for Nimonic 263). The damages have been observed by optical and scanning electron microscopy, together with the energy dispersive analysis. The Vickers microhardness measurements under 0.5 and $1 \mathrm{~kg}$ load have been performed as well.

\section{Results and discussion}

Irradiated regions of Hastelloy X samples are presented in Fig. 2a (optical microscope) and b (scanning electron microscope, SEM). The regions 1, 2 and 3 correspond to the irradiation periods of 60,30 and $15 \mathrm{~s}$, respectively. Plasma plume appeared at all cases; however, in the case 3 , the plume was more intense than in the previous cases. After $15 \mathrm{~s}$ of the ablation in the case 3, the sample was displaced during irradiation. This is noticeable as a line-shaped ablation in Fig. 2. Each region shows three areas: pear-shaped ablated area (inner), surrounding ring (middle) and the outer ring.

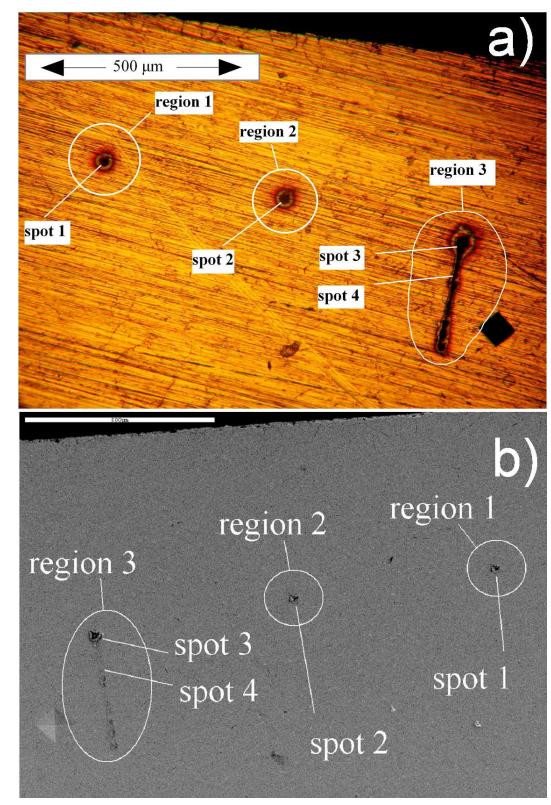

Fig. 2. Photos of irradiated regions of Hastelloy $\mathrm{X}$ (white horizontal bars denote $500 \mu \mathrm{m}$ ): (a) optical microscope, and (b) SEM.

The shape of the ablated area is due to the coma of incoming beam. The surrounding (middle) and outer rings kept the original surface structure of the base material. The middle ring also kept the surface color. Changed color of the outer ring suggests the appearance of the deposited material. Due to the regular shape of the outer ring, it is assumed that the deposition occurred directly from the plasma plume without melted phase. SEM micrograph (Fig. 3a) also indicates the non-existence of melted phase in the middle and outer rings.

The comparison of irradiated regions between Hastelloy X (a) and Nimonic 263 (b) samples is presented in

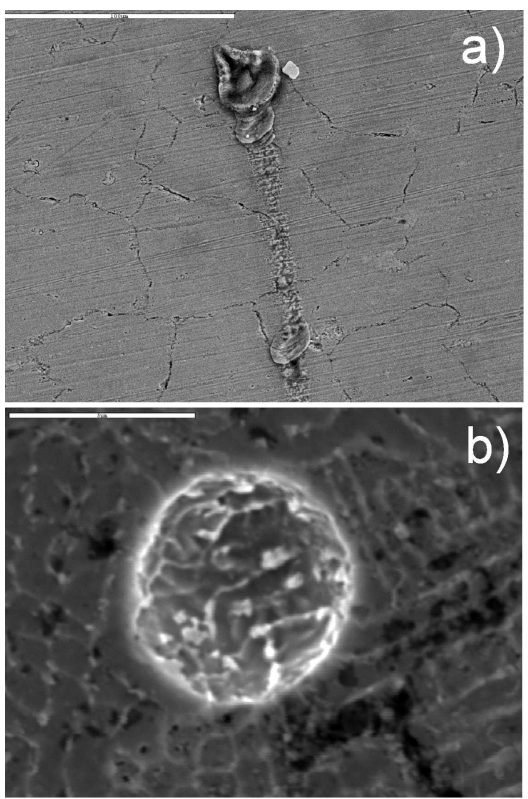

Fig. 3. Micrographs of fs beam irradiated regions: (a) Hastelloy X, $15 \mathrm{~s}$ and $1.802 \mathrm{~W}$ of average power; (b) Nimonic 263, $60 \mathrm{~s}$ and $1.260 \mathrm{~W}$ of average power. White horizontal bars in upper left corners denote $100 \mu \mathrm{m}(\mathrm{a})$ and $5 \mu \mathrm{m}(\mathrm{b})$.

Fig. 3. Hastelloy $\mathrm{X}$ ablated area in the irradiated region shows larger diameter and the appearance of melted phase, while Nimonic 263 kept the surface structure of the base material which implies that the melting did not occur. The reasons might be: less average power of the fs beam and higher microhardness of unaffected regions in the case of Nimonic $263\left(268 \mathrm{HV}_{1}\right)$, compared to Hastelloy $\mathrm{X}\left(196 \mathrm{HV}_{1}\right)$.

The results of the energy dispersion spectroscopy (EDS) analysis show the increase of the $\mathrm{Al}, \mathrm{Si}, \mathrm{Cr}$ and $\mathrm{Fe}$ contents at the spots of ablated areas (Table II). At the same time, the contents of $\mathrm{Ni}$ and Mo decreased. The content of $\mathrm{W}$ also increased at the spots of ablated areas and their vicinities. The existence of $\mathrm{S}$ and increased content of $\mathrm{Fe}$ hint at the possibility of $\mathrm{FeS}$ forming, which influences the antifriction and wear-resistance properties of the material [12]

Both optical and scanning electron microscopy analyses show that initial microcracks, commonly initiated - among other causes - by topologically closed-packed (TCP) phases $[3,13]$ did not appear. Because of that and because it was noticed that the content of Mo, Co and $\mathrm{Ni}$ decreased, it is also assumed that the formation of TCP phases did not occur.

Microhardness measurements were performed with $500 \mathrm{~g}$ load. The result, the average of 5 measurements on the base material, was $200 \mathrm{HV}_{0.5}$. In the vicinity of the ablation area (Fig. 4a), the microhardness remained the same. At the ablation area which showed the greatest appearance of plasma plume, the microhardness increased to $213 \mathrm{HV}_{0.5}$ (Fig. 4b). Increased both the microhard- 
TABLE II

The results of EDS analysis, for ablated areas depicted in Fig. $2 b$

\begin{tabular}{c|c|c|c|c}
\hline \hline Element & $\begin{array}{c}\text { \% weight in } \\
\text { spot 1 }\end{array}$ & $\begin{array}{c}\text { \% weight in } \\
\text { spot 2 }\end{array}$ & $\begin{array}{c}\text { \% weight in } \\
\text { spot 3 }\end{array}$ & $\begin{array}{c}\text { \% weight in } \\
\text { spot 4 }\end{array}$ \\
\hline $\mathrm{Al}$ & 0.26 & 0.70 & 0.85 & 0.18 \\
$\mathrm{Si}$ & 1.92 & 1.27 & 1.03 & 1.23 \\
$\mathrm{~S}$ & 1.47 & 1.25 & 0.94 & 1.68 \\
$\mathrm{Ca}$ & 0.25 & 0.42 & 1.16 & 0.17 \\
$\mathrm{Cr}$ & 23.6 & 24.90 & 20.70 & 24.81 \\
$\mathrm{Mn}$ & 1.12 & 1.30 & 1.13 & 1.10 \\
$\mathrm{Fe}$ & 22.04 & 23.07 & 24.01 & 17.30 \\
$\mathrm{Co}$ & 1.81 & 1.81 & 1.50 & 1.88 \\
$\mathrm{Ni}$ & 40.67 & 40.07 & 40.03 & 42.99 \\
$\mathrm{~W}$ & 0.72 & 0.68 & 0.34 & 1.84 \\
$\mathrm{Mo}$ & 6.14 & 4.40 & 6.08 & 6.84
\end{tabular}

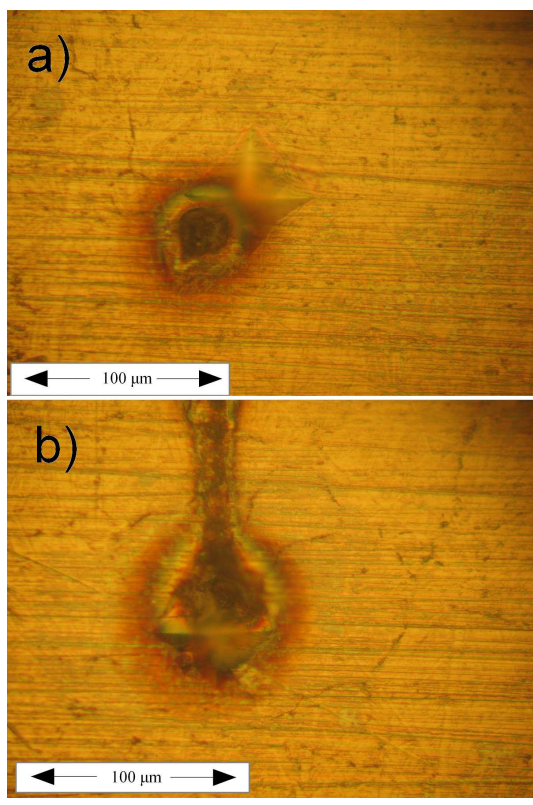

Fig. 4. Photos (optical microscope, white horizontal bars denote $100 \mu \mathrm{m}$ ) of ablated areas of Hastelloy X after microhardness measurements: (a) irradiated region 2 ; (b) irradiated region 3 .

ness and the content of $\mathrm{W}$ and $\mathrm{Cr}$ indicate the possibility of carbide formation [13].

\section{Conclusion}

We have investigated the regions of selected nickel-base superalloys, Hastelloy X and Nimonic 263, after the irradiation by fs laser beam.
In the case of Hastelloy X, plasma plume, followed by melting phase, appeared in each irradiation. The interaction affected zone consists of three areas: pear-shaped ablated area (beam affected zone), and surrounding and outer rings. The material deposited in the outer ring directly from plasma plume. In the case of Nimonic 263, the melted phase did not occur due to the characteristics of the material as well as of the laser beam.

As for the EDS analyses, Hastelloy $\mathrm{X}$ showed the increase in the content of $\mathrm{Al}, \mathrm{Si}, \mathrm{Cr}, \mathrm{Fe}$ and $\mathrm{W}$, and the decrease in Mo, Co and Ni. Optical microscopy and SEM did not reveal any cracks and TCP phases. The ablated areas of Hastelloy $\mathrm{X}$ showed the increase in microhardness, compared to the base material.

Above mentioned changes of the base material by fs laser beam ablation process might be of interest for the construction of ultrafine surface structures.

\section{Acknowledgments}

The authors would like to thank the Ministry of Science of the Republic of Serbia for kind support under numbers 141003 and 14067.

\section{References}

[1] R. Schafrik, R. Sprague, Key Eng. Mater. 380, 113 (2008).

[2] G.V.S. Murthy, S. Ghosh, M. Das, G. Das, R.N. Ghosh, Mater. Sci. Eng. A 488, 398 (2008).

[3] R.C. Roger, The Superalloys, Fundamentals and Applications, Cambridge University Press, New York 2006.

[4] B.N. Chichkov, C. Momma, S. Nolte, F. von Alvensleben, A. Tuennermann, Appl. Phys. A 63, 109 (1996).

[5] G. Dumitru, V. Romano, H.P. Weber, M. Sentis, W. Marine, Appl. Phys. A 74, 729 (2002).

[6] C.Y. Chien, M.C. Gupta, Appl. Phys. A 81, 1257 (2005).

[7] S. Bruneau, J. Hermann, G. Dumitru, M. Sentis, E. Axente, Appl. Surf. Sci. 248, 299 (2005).

[8] K. Paivasaari, J.J.J. Kaakkunen, M. Kuittinen, T. Jaaskelainen, Opt. Express 15, 13838 (2007).

[9] S. Ma, J.P. McDonald, B. Tryon, S.M. Yalisove, T.M. Pollock, Metall. Mater. Trans. A 38, 2349 (2007).

[10] Q. Feng, Y.N. Picard, H. Liu, S.M. Yalisove, G. Mourou, T.M. Pollock, Scr. Mater. 53, 511 (2005).

[11] S. Amoruso, R. Bruzzese, X. Wang, N.N. Nedialkov, P.A. Atanasov, J. Phys. D, Appl. Phys. 40, 331 (2007).

[12] L.-N. Zhu, G.-I. Li, H.-D. Wang, B.-S. Xu, J.-J. Liu, Mater. Lett. 62, 163 (2008).

[13] Metals Handbook, Ed. J.M. Davies, ASM International, 2001. 